\title{
DESIGN AND MANUFACTURING OF PROTOTYPE FOR ORANGE GRADING USING PHOTOTRANSISTOR
}

\section{Gamea, G. R. ", Aboamera, M. A. ${ }^{*}$ and Mohmed, M. E. ${ }^{* *}$ ABSTRACT}

Fruits are usually graded according to their quality. The purpose of the grading is to grad fruit into uniform categories (according to size, shape, weight, color and ripening stage). So fruit can be classified to different grades according to the requirements of the market. Due to the lack of the small grading machinery for small farms and the high prices of large grading machinery, this study aimed to designing, manufacturing and performance evaluating of a prototype for orange grading based on the dimensions of the fruit, which take place without physical contact. The prototype uses different successively operating components, such as phototransistors and actuators, each performing a specific task. The operating principle depend on the phototransistor, signal gathering circuit a processing circuit and output circuit for distributing unit. When it works, the system receives digital signals produced by fruits that shadow the light from a phototransistor sensor during fruit measuring. These digital signals processed by an electronic circuit and the fruit's sizing level are deduced. Then, the system will output switch signals to open the sorting switches according to fruits' size. Testing of the grading prototype results was statistically factorial in completely randomized design, featuring three control factors (conveyor chain velocity, sphericity percentage of fruit and stopping time) and three performance evaluation parameters (grading efficiency, damage percentage and productivity). The result showed that the best degree of grading efficiency obtained with the best degree of damage percentage were at $0.15 \mathrm{~m} / \mathrm{s}$ chain velocity and $1.5 \mathrm{sec}$ Stopping time. The best obtained values of grading efficiency were $(92.2 \%)$ with $(7.1 \%)$ damage fruit. The energy required was $160.2 \mathrm{Watt} / \mathrm{h}$. The cost of materials and manufacturing of the final grading prototype was 10000 L.E. The cost of grading prototype per hour was (4.918 L.E).

Key words: Grading, Orange, Phototransistor, Electronic circuit.

\footnotetext{
* Associate prof. of Agric. Eng., Fac. of Agric., Minoufiya Univ.

**Associate lecturer of Agric. Eng., Fac. of Agric., Minoufiya Univ.
} 


\section{INTRODUCTION}

orting and grading are terms which frequently used interchangeably in the food processing industry. Sorting is a separation based on a single measurable property of raw material units, while grading is the assessment of the overall quality of a food using a number of attributes. Grading of fresh product may also be defined as sorting according to quality, as sorting usually upgrades the product (Brennan, 2006). Fresh market fruits like apples are graded into quality categories according to their size, color and shape and to the presence of defects. The two first quality criteria are actually automated on industrial graders, but fruits grading according to the presence of defects is not yet efficient and consequently remains a manual operation, repetitive, expensive and not reliable (Leemans and Destain, 2004). In recent ten years, operations in grading systems for fruits and vegetables became highly automated with mechatronics, and robotics technologies. Machine vision systems and near infrared inspection systems have been introduced to many grading facilities with mechanisms for inspecting all sides of fruits and vegetables (Kondo, 2009). Nondestructive quality evaluation of fruits is important and very vital for the food and agricultural industry. Traditionally grading of fruits is performed primarily by visual inspection using size as a particular quality attribute. Image processing offers solution for automated fruit size grading to provide accurate, reliable, consistent and quantitative information apart from handling large volumes, which may not be achieved by employing human graders (Sudhakara and Renganathan, 2002).

Tabatabaeefar et al., (2000) Presented an approach to automate fruit sorting using information that is acquired from selected sensors which measure and quantify parameters (color, firmness, size, weight) that are indicators of fruit quality. The information was used as input to a recurrent auto associative memory that classified the fruits into four maturity stages (Ozer et al.,1995). Moreda et al., (2009) reported that, in order to size oranges based on one diameter, the intermediate diameter (D) is recommended, not the length (L) of orange. Different electronic systems have been developed for non destructive determination of horticultural produce dimension size. 
Orange fruit can be classified manually, but these process is slow, high labor costs, worker fatigue, inconsistency, variability, and scarcity of trained labor and grading is done by visual inspection that could be error prone, as well as the uniformity will be much better when sizing is done mechanically. Especially when graded by electronic machine which consist of mechanical devices controlled electronically. This is a better method, since it produces a much more uniform classification. Due to the lack of the small grading machinery for small farms and the higher prices of large grading machinery, this study aimed to designing, manufacturing and evaluating the performance of a prototype for orange grading which comprised a grading unit and a distributing unit based on the dimensions of the fruit.

\section{MATERIALS}

\section{MATERIALS AND METHODS}

The materials and equipment which were used in this study can be summarized as follows:

\section{Grading prototype}

The designed prototype as presented in figures (1 and 2) consists of the following main parts:

\section{1-Frame}

The frame was constructed from steel angle $(40 \times 40 \mathrm{~mm})$ with $3 \mathrm{~mm}$ thickness and square shape iron steel $(40 \times 40 \mathrm{~mm})$ with $2 \mathrm{~mm}$ thickness welded together to connect all prototype unit.

2-Feeding unit

The feeding unit consists of three parts, namely, feeding hopper, conveyor chain and electrical direct current motor (12V, 4A.DC).

3- Sensors unit

The main purpose of the sensors unit is to measures the vertical width or height of a fruit. The measure occur during as it passes between two lateral vertical arrays of optical transducers based on the blocking of light. One of which is equipped with light emitting diodes (LEDs) and the other with phototransistors. The sensors unit as sketched in figure (3).

4- Distributing gates unit

Distributing gates unit as sketched in figure (4) consists of four electrical DC motors, Frame and four gates. 

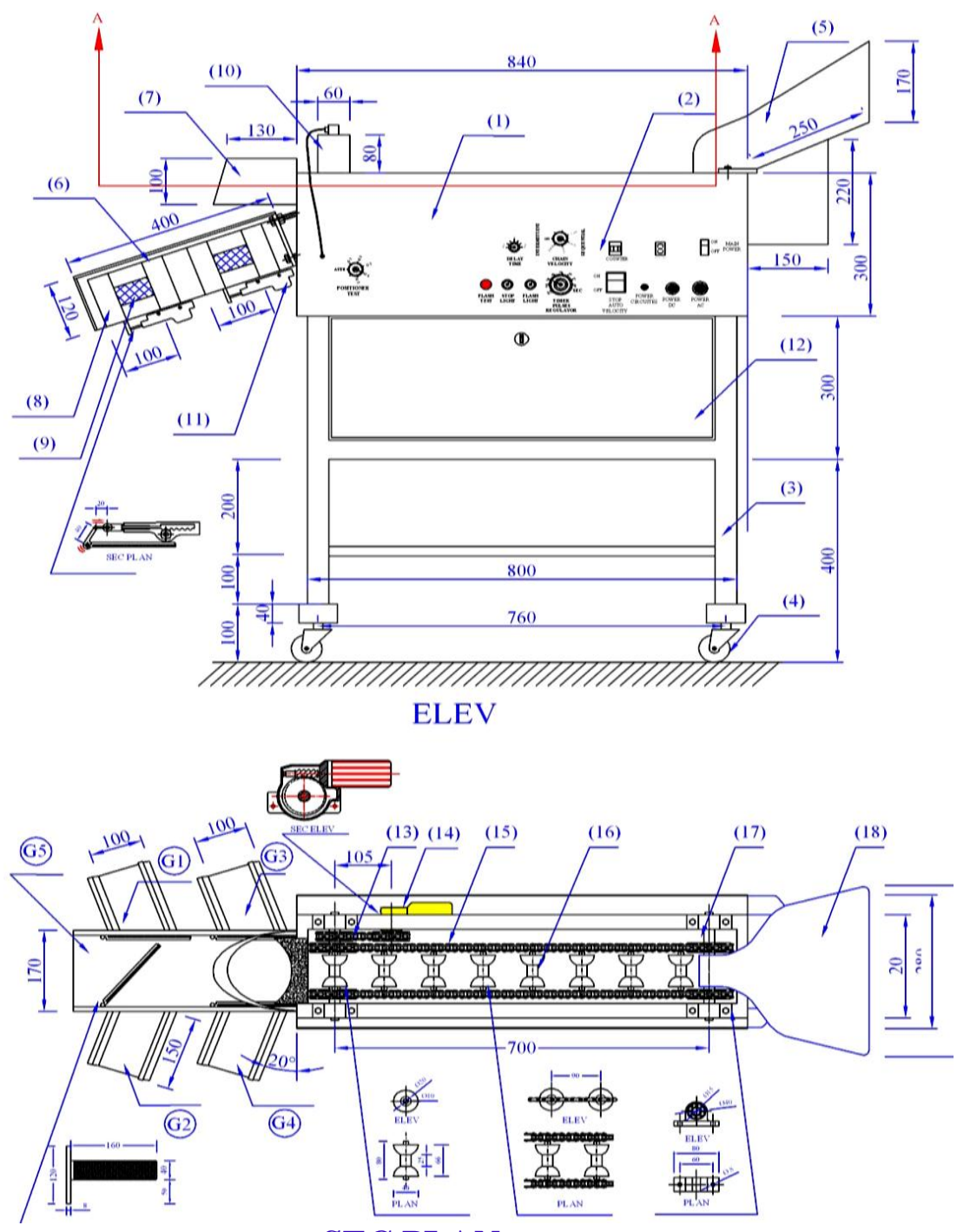

SEC PLAN

1- Housing;

6- Gates unit;

11

2- Control switch;

7- Cover;

3- Frame

8- Gates;

gate;

15- Conveyor chain;

4- Wheel

9- Sponge cover;

5- Hopper holder;

10- Sensors unit;

12- Circuit box;

13- Chain;

14- Electric motor of conveyor;
16- Rubber pulley;

17- Gear;

18- Feeding hopper.

DIMS in mm

Fig. (1): Elev. and sectional plan of grading prototype (distributing gates). 

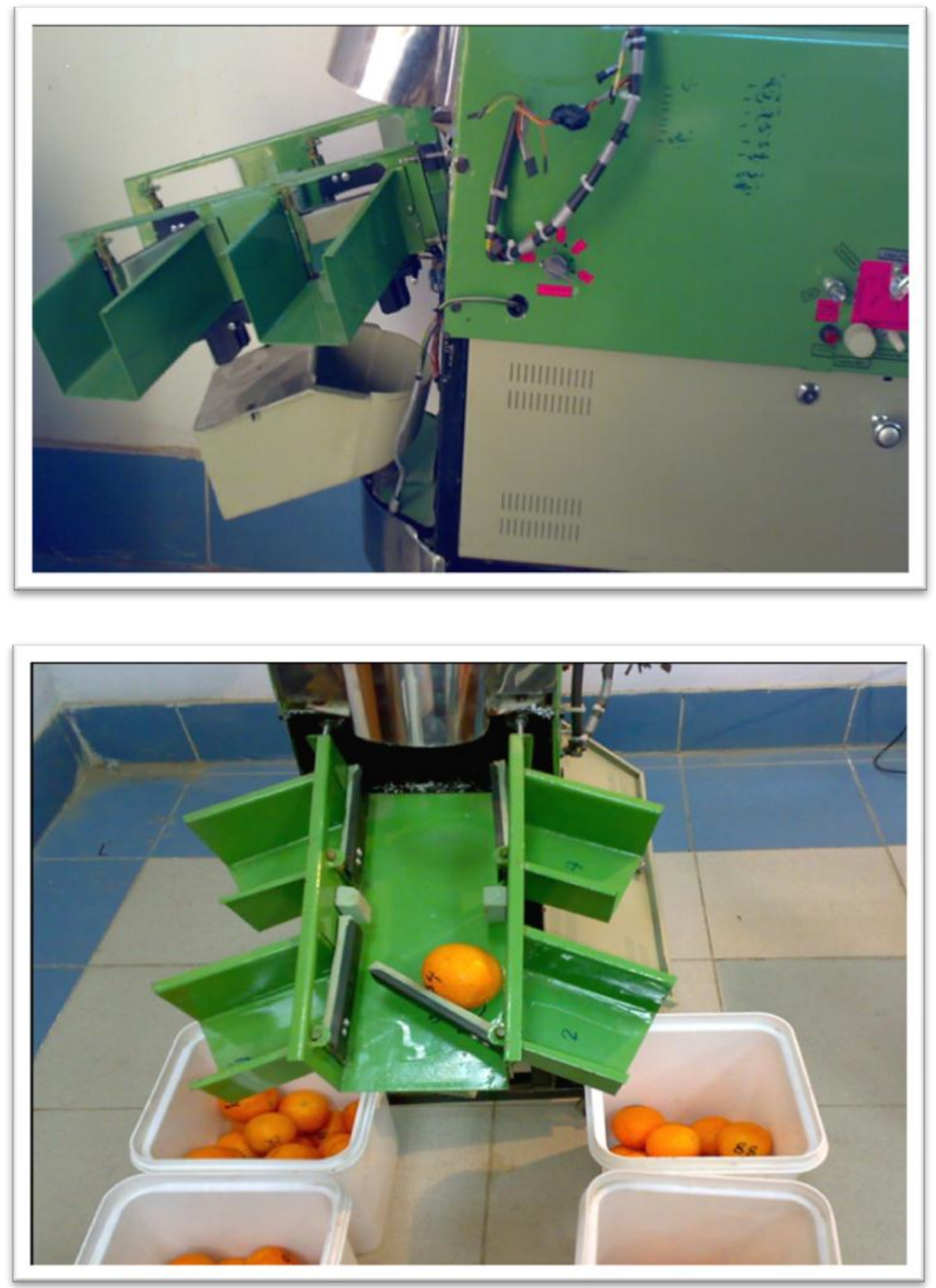

Fig. (2): Image of grading prototype (distributing gates)

\section{5- Electronic control unit}

The control unit has been comprised a number of electronic circuits for controlling the feeding rates by control the feeding chain speed. The control system also measures the diameter of fruits individually by 
optical circuit which has been controlled in the position of the fruit outlet according to its category that has been determined by different optical circuit. The control unit consists of the following main electronic circuits.

\section{a. Power control system}

The power system consists of (Transformers, Diode bridge and fullwave rectification, AC to DC Power supplies, voltage regulators and power supply distribution circuit).

\section{b. Timing control system}

The timing system, which has been used in the proposed grading prototype consisted of three timer. The first to control the time delay of light, the second to control the lighting time and the third to control the stopping time of fruit in front of sensors unit . Figure (5) shows a timing diagram of operations and the sensors or motors either triggering events or causing motion using Timing Tool Editor 3.0.1 (2009) program.

\section{c. Measuring control system}

The main function of the measuring control system based on blocking light was to determine the dimension of the graded fruits as a voltage value. The system has been consisted of phototransistor light sensor and light-emitting diode (LED) light source. The application circuit that was used in this study shown in figure (6). This circuit has been consisted of two IC LM339, two IC 7442, two IC 4069, one IC uln2003, four relays, four capacitor, four diode, eight Phototransistor and eight variable resistor. The value of variable resistor depends on the input light intensity, ambient temperature, response speed, etc. This circuit is similar to the photoresistors circuit but the differences in sensor used only.

\section{d. Distributing control system}

The function of gates control circuit was to control of opening the gate which direct the fruit to its category falling position. The gates control circuit has been consisted of six relay $12 \mathrm{~V}$.

\section{Grading fruits}

The grading prototype was used to grade orange (Navel variety). The fruit was obtained from the private farm in Minofiya Governorate, Egypt. 


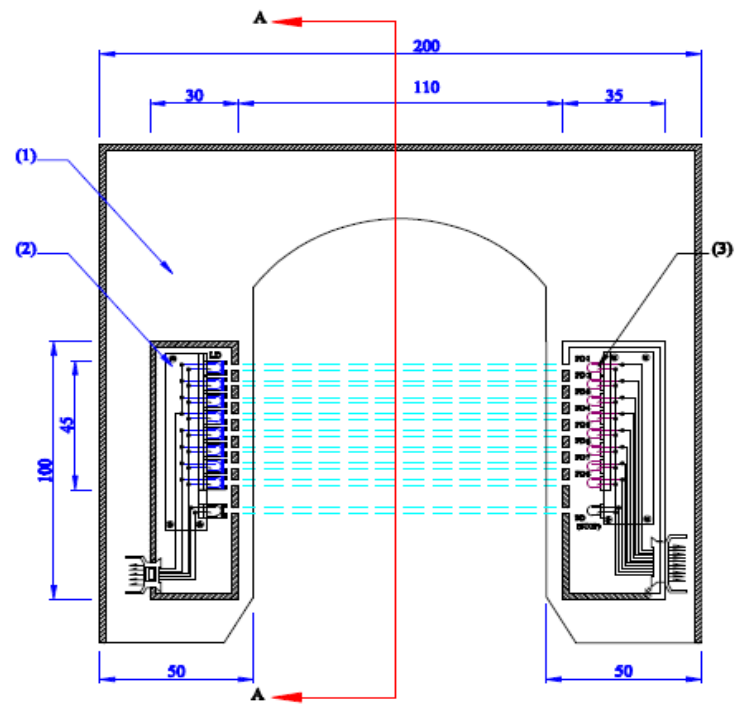

SEC ELEV AT B-B

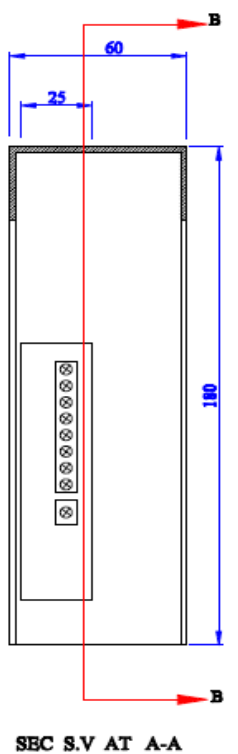

SEC S.V AT A-A

1-Housing, 2-Array of light emitting diode, 3-Array of optical sensor Fig. (3): Schematic diagram of sensors unit.

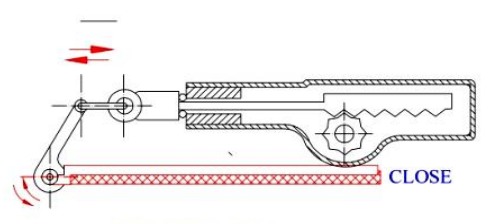

SEC PLAN

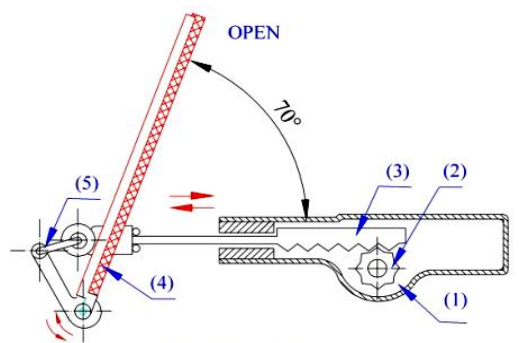

SEC PLAN

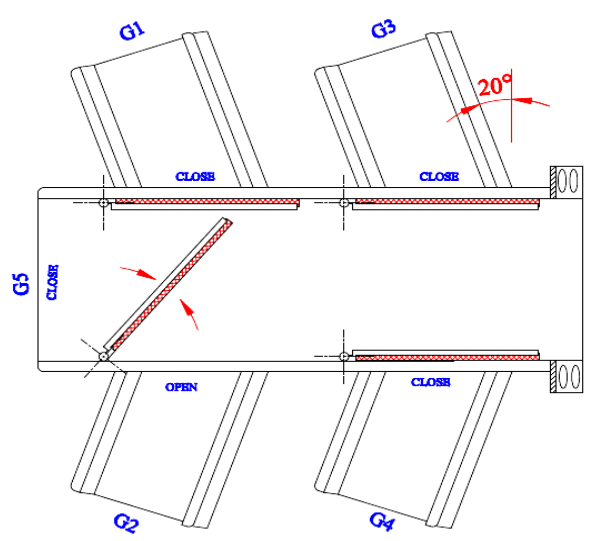

1- DC motor; 2- Pinion; 3- Rack; 4- Gate; and 5-Connecting road.

Fig. (4): Distributing gates with the frame and four DC motor 


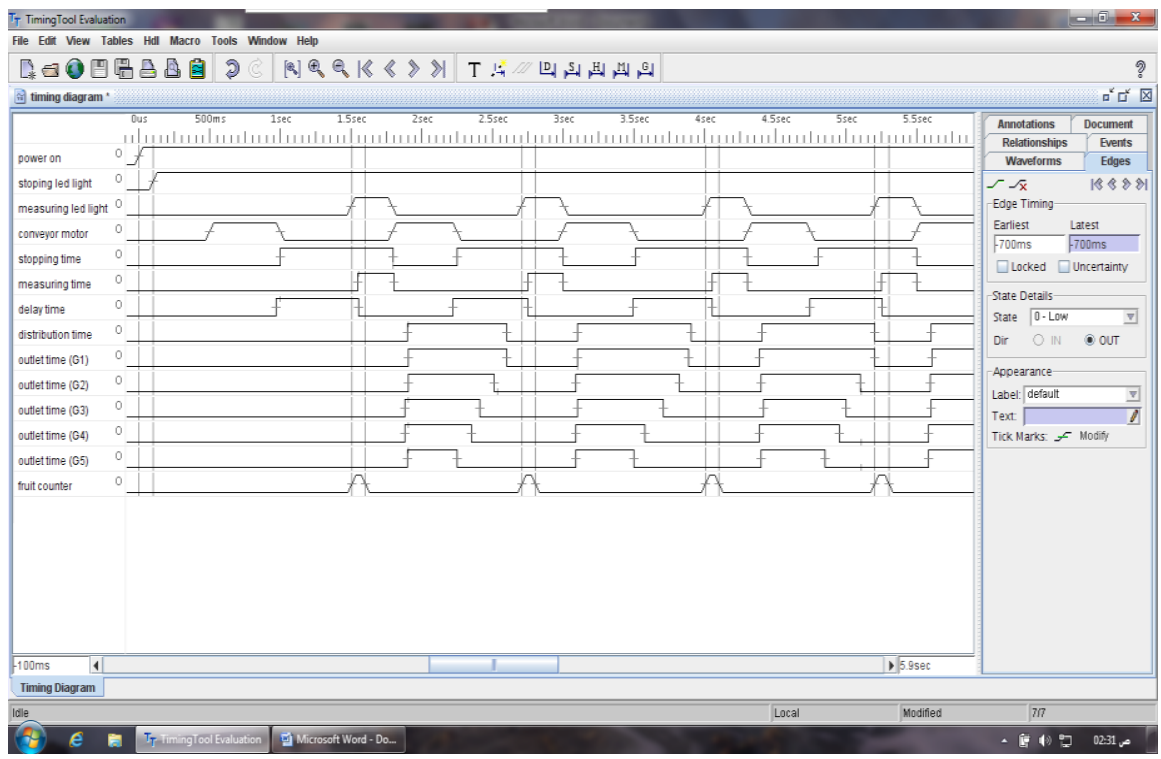

Fig(5) Interface of (Timing Tool Editor 3.0.1 (2009)) program

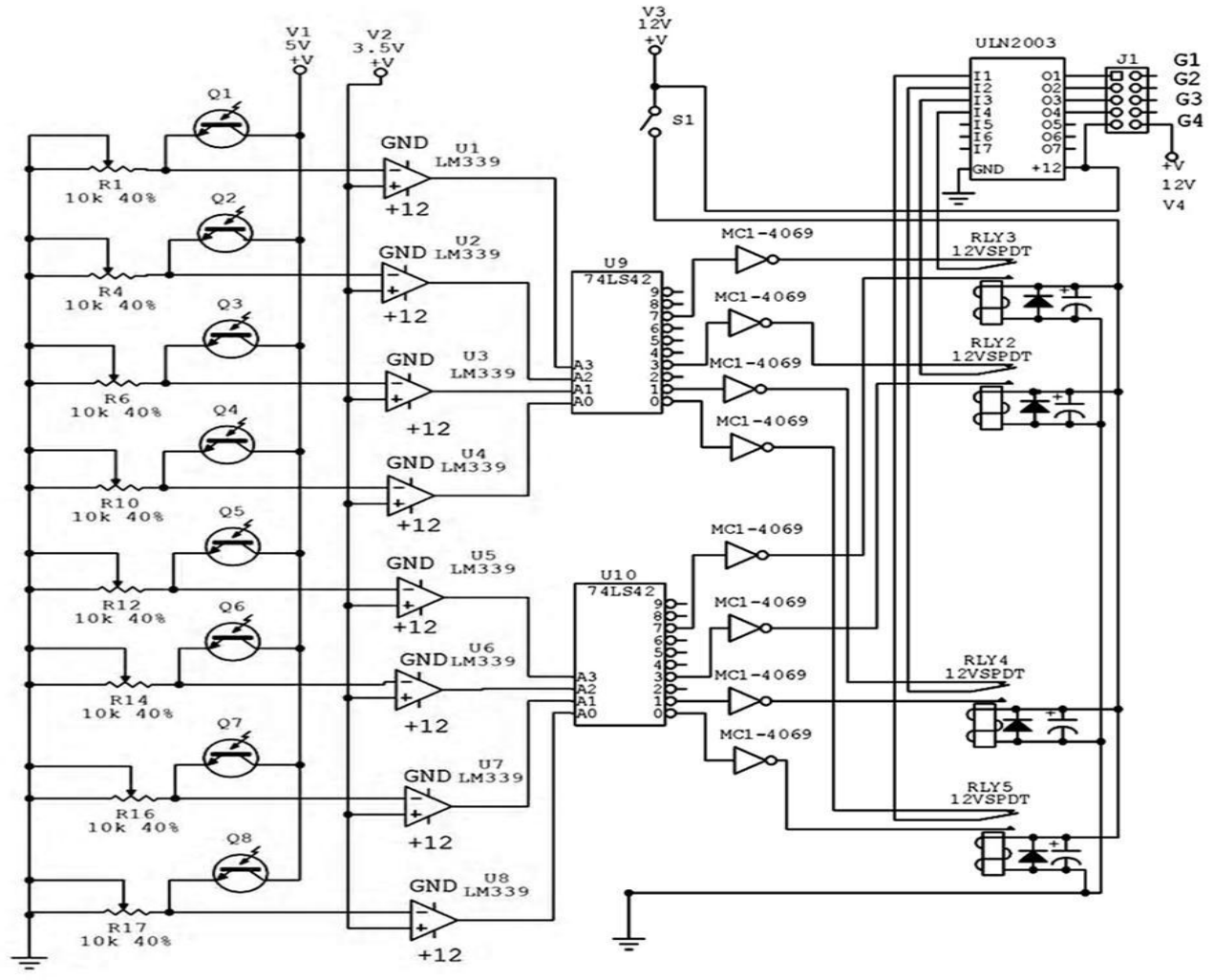

Fig(6) Phototransistor circuit. 
PROCESS ENGINEERING

\section{METHODS}

The grading prototype was designed, manufactured and its performance evaluated in the workshop of Agricultural Engineering Department, Faculty of Agriculture, El-Menoufiya University. It is also characterized by a simple design; most of its parts are locally available materials, low costs manufacture and ease of construction.

\section{$\underline{1-T e s t e d ~ f a c t o r s ~ f o r ~ o r a n g e ~ g r a d i n g ~}$}

1- Speed of conveyor chain, four-speed $(0.10,0.15,0.20,0.25 \mathrm{~m} / \mathrm{s})$.

2- Stopping time of fruit, four periods $(1,1.5,2,2.5 \mathrm{sec})$ with measure signal delay time $(0.5,1,1.5,1.5 \mathrm{sec})$ respectively.

3- Spherisity (less than $90 \%$, between $90 \%$ to $95 \%$, greater than $95 \%$ ).

\section{Measurements}

The following measurements were carried out during the present study:

\section{Physical characteristics of crops}

1. Determination of fruit dimensions

The mean dimensions length (L), width (W), thickness (T) for each fruit estimated by digital vernier caliper with accuracy of $0.01 \mathrm{~mm}$.

2. Volume

Volume of the individual orange fruit was measured by the liquid displacement method using toluene $\left(\mathrm{C}_{7} \mathrm{H}_{8}\right)$.

3. Determination of particle densities

Fruit density was calculated for a random one hundred sample of fruits as follows:

$$
D_{r}=M / V_{1}, \mathrm{~g} / \mathrm{cm}^{3}
$$

Where:

$D_{r}=$ Particle density of the individual fruit, $\mathrm{g} / \mathrm{cm} 3$;

$M=$ Mass of the individual fruit, $g$;

$V_{1}=$ Volume of the individual fruit, $\mathrm{cm} 3$.

4. Determination of static and dynamic coefficient of friction

a. static coefficient of friction

The friction angle for fruits was measured against two structural materials, rubber and galvanized iron. The board on which the 
material was fixed, was tilted slowly and gradually until the fruits overcomes the static friction and begin to slide downwards over the plane.

b. Dynamic coefficient of friction

A measuring device showed in fig. (7) was designed and fabricated in Agricultural Engineering department, Faculty of Agricultural, Minoufiya University, it was used to measure the dynamic coefficient of friction for orange fruits on two different surfaces disk (rubber and galvanized iron) $40 \mathrm{~mm}$ diameter.

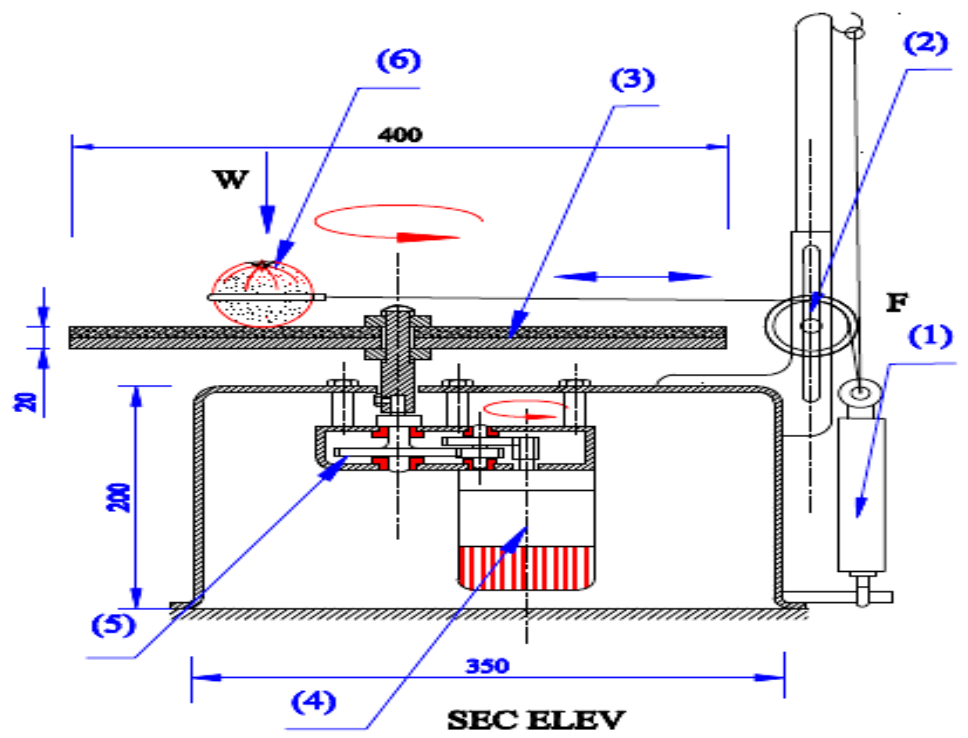
1. digital balance,
3.rotating disk,
5. gear box
2. roller,
4. motor,
6 . fruit

Fig. (7): Schematic diagram of coefficient of static friction apparatus.

\section{Sphericity}

According to the most commonly used definition, sphericity is the ratio of volume of solid to the volume of a sphere that has a diameter equal to the major diameter of the object so that it can circumscribe the solid sample. For a spherical particle of diameter $D p$, sphericity is equal to (Mohsenin, 1970). 


$$
\begin{aligned}
& \text { Sphericity }=\frac{\text { geometric mean diameter }}{\text { major diameter }}=\frac{(a b c)^{\frac{1}{3}}}{a} \ldots \ldots . . . . .(2) \\
& \text { where: } \\
& a=\text { longest intercept, } \\
& b=\text { longest intercept normal to } a, \\
& c=\text { longest intercept normal to } a \text { and } b .
\end{aligned}
$$

\section{Projected area}

Projected area of orange fruit obtained from a proposed device is based on image processing. Captured images from a camera were transmitted to a computer card which works as an analog to digital converter. Digital images were then processed to the software and the desired parameters were determined.

\section{Evaluation parameter of grading machine}

1. Prototype efficiency, \%:

The efficiency of the prototype determined as the grading efficiency. The total grading efficiency of the prototype was estimated according to Klenin et al., (1985) using the following formula:

$$
\eta_{G}=\left(m_{1}+m_{2}+m_{3}+m_{4}+m_{5}\right) / m
$$

Where:

$$
\begin{aligned}
& \eta_{G}=\text { total prototype grading efficiency, } \\
& m=\text { total mass of orange in } \mathrm{kg}, \\
& m_{1}, m_{2}, m_{3}, m_{4} \text { and } m_{5}=\text { mass of orange in different collected grading } \\
& \text { oranges from collected box } A, B, C \text { and } D .
\end{aligned}
$$

2. Damage percentage

Damage percentage calculated according to Mcgechan (1980) as follow:

$$
M_{d}=\frac{m_{1}-m_{2}}{m_{1}} \%
$$

Where:

$$
\begin{aligned}
& M_{d}=\text { damage percentage }(\%) ; \\
& m_{1}=\text { total mass of fruit before grading }(\mathrm{kg}) ; \\
& m_{2}=\text { total mass of un damage fruit after grading }(\mathrm{kg}) .
\end{aligned}
$$

3. Electric power

A digital clamp meter and Voltmeter were used for measuring current intensity and voltage respectively. The electric power $(\mathrm{P}$, 
PROCESS ENGINEERING

Watt) was calculated based on current intensity (I, Ampere) and the voltage (V, volt) measurements, using the following formula:

$$
P=\operatorname{Cos} \emptyset \text {. I. V. }
$$

Where:

Cos Ø Power factor (being equal to 0.85)

\section{Prototype productivity}

Prototype productivity, which varies with the grading time period per hour and the weight of fruit per period. The productivity of the prototype can be determined by using the following equation:

Prototype productivity, $(\mathrm{kg} / \mathrm{h})=W / P_{n}$

Where:

$W=$ The weight of fruit per period, $\mathrm{kg}$;

$P_{n}=$ Grading period time per hour.

\section{Cost analysis:}

The operation cost of grading prototype was calculated according to (Awady, 1978) formula based on the initial cost of prototype, interest on capital, cost of the power requirements $\left(\mathrm{P}_{\mathrm{c}}\right)$, cost of maintenance, and wage of operator according to the following:

$C=P / h(1 / e+i / 2+t+r)+\left(P_{c} \times S\right)+W / 144$

Where:

$C=$ Hourly cost (L.E/h),

$P=$ Price of prototype (10000 L.E),

$h=$ Yearly operating hours $(1344 \mathrm{~h})$,

$e=$ Life expectation (10 year),

$i=$ Interest rate (10\%),

$t=$ Overheads ratio (3\%),

$r=$ Repairs ratio of the total investment (1\%),

$P_{c}=$ power requirements $(0.16 \mathrm{~kW})$,

$S=$ Price of power requirements per $(0.2 \mathrm{~kW} / \mathrm{h})$,

$W=$ Labour wage rate per month in (500 L.E),

$144=$ Reasonable estimation of monthly working hours.

\section{RESULTS AND DISCUSSIONS}

Results obtained can be reported as follows:

\section{Physical characteristics of the fruits}

1-The physical characteristics of orange (Navel), that grading under the investigated prototype can be summarized as follows: 
Length $(75.22 \pm 5.74 \mathrm{~mm})$ Width $(71.91 \pm 4.39 \mathrm{~mm})$, density $\left(0.91 \pm 0.02 \mathrm{~g} / \mathrm{cm}^{3}\right)$, volume $\left(221.97 \pm 38.87 \mathrm{~cm}^{3}\right)$, weight $(201.62 \pm 35.22 \mathrm{~g})$, sphericity percentage $(97.1 \pm 3.17 \%)$, the minimum fruit falling height which cause damage $(64.29 \pm 13.36$ $\mathrm{cm})$, coefficient of dynamic friction of the fruits on galvanized iron sheet $(0.46 \pm 0.02)$ and on the rubber $(0.71 \pm 0.01)$, the static coefficient of friction on galvanized iron sheet $(0.48 \pm 0.02)$ and on rubber $(0.72 \pm 0.02)$ and the rolling angle $\left(13.57 \pm 2.44^{\circ}\right)$.

\section{Performance evaluation of grading prototype}

2.1. The grading efficiency

Fig (8) shows the relationship between the conveyor chain velocity and grading efficiency for orange at different values of stopping time $(1,1.5$, 2 and $2.5 \mathrm{sec})$ and different percentage of sphericity $(<90 \%, 90: 95 \%$ and $>95 \%)$. The result showed that, grading efficiency decreased with increasing conveyor chain velocity, decreasing the stopping time and increasing the sphericity percentage. This decreasing may due to increasing the feeding rate of fruit. This would lead to lower measurement accuracy due to non-uniformity of movement and the cause no stand the fruit in specific measure spaces due to the fruit acquisition of large kinetic energy. The reason also is due to the low speed sensitive stop response fruits because of its cohesion, shows that when the succession of large-sized fruits. Therefore, low efficiency is more significant especially in the large group size. The obtained minimum grading efficiency was $87.08 \%$ obtained at the conveyor chain velocity and stopping time $0.25 \mathrm{~m} / \mathrm{s}$ and $1 \mathrm{sec}$ respectively and sphericity percentage less than $90 \%$. While, the obtained highest grading efficiency was $96.82 \%$ at the conveyor chain velocity and stopping time $1 \mathrm{~m} / \mathrm{s}$ and $2.5 \mathrm{sec}$ respectively and sphericity percentage more than $95 \%$. It is clear that, for all conveyor chain velocities the lowest stopping time $1 \mathrm{sec}$ and lowest sphericity percentage caused a big reduction in grading efficiency. The interactions between four different conveyor chain velocities and stopping time values and sphericity percentage levels were highly significant. 

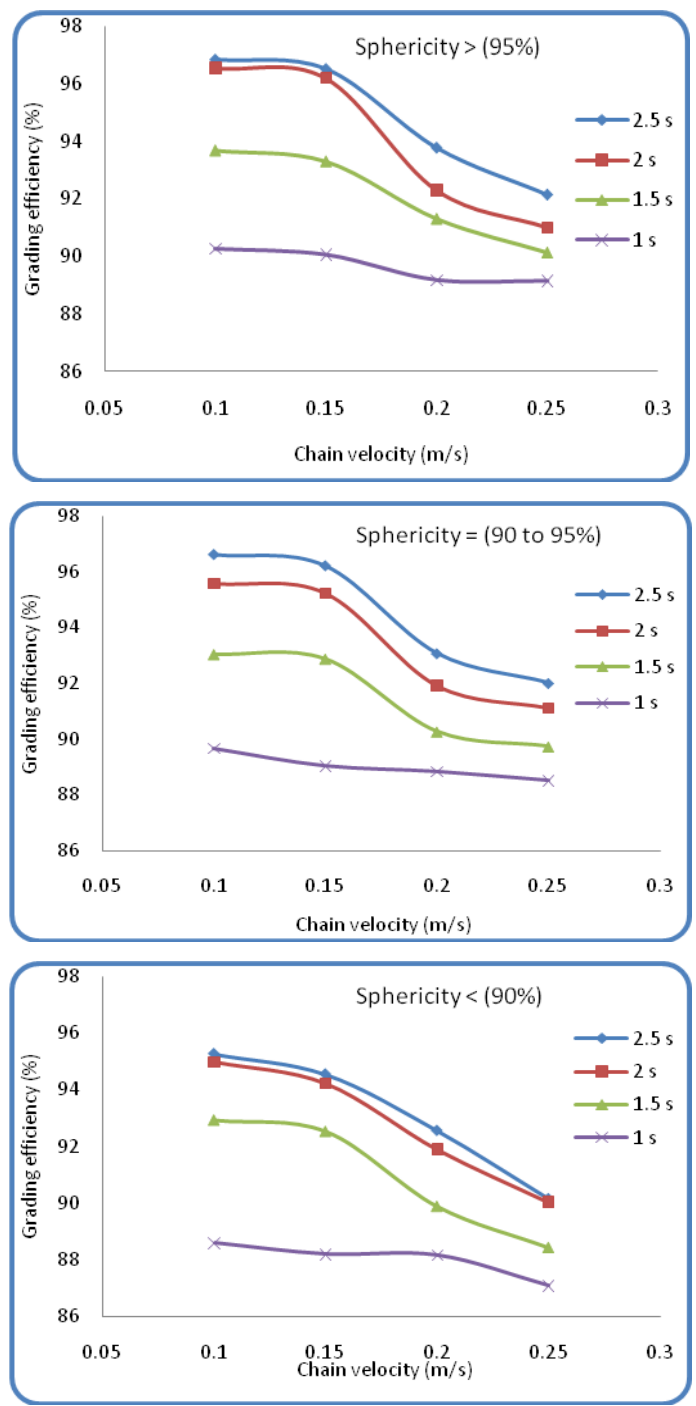

Fig. (8): Effect of conveyor chain velocity on the grading efficiency at different values of stopping time, sphericity percentage and distributing gates system for orange.

\subsection{The damage}

Fig (9) indicated the effect of conveyor chain velocity on the mean value of the damage percentage at different values of stopping time and sphericity percentage for orange. The effect of the interactions among conveyor chain velocities and stopping time on damage percentage were highly significant. The highest damage percentage 
$(11.92 \%)$ was observed at the interaction of $0.25 \mathrm{~m} / \mathrm{s}$ conveyor chain velocity and sphericity percentage less than $90 \%$ and $1 \mathrm{sec}$ stopping time. While, the lowest damage percentage (1.18\%) was observed at the interaction of $0.1 \mathrm{~m} / \mathrm{s}$ conveyor chain velocity and sphericity percentage more than $95 \%$ and $2.5 \mathrm{~s}$ stopping time.
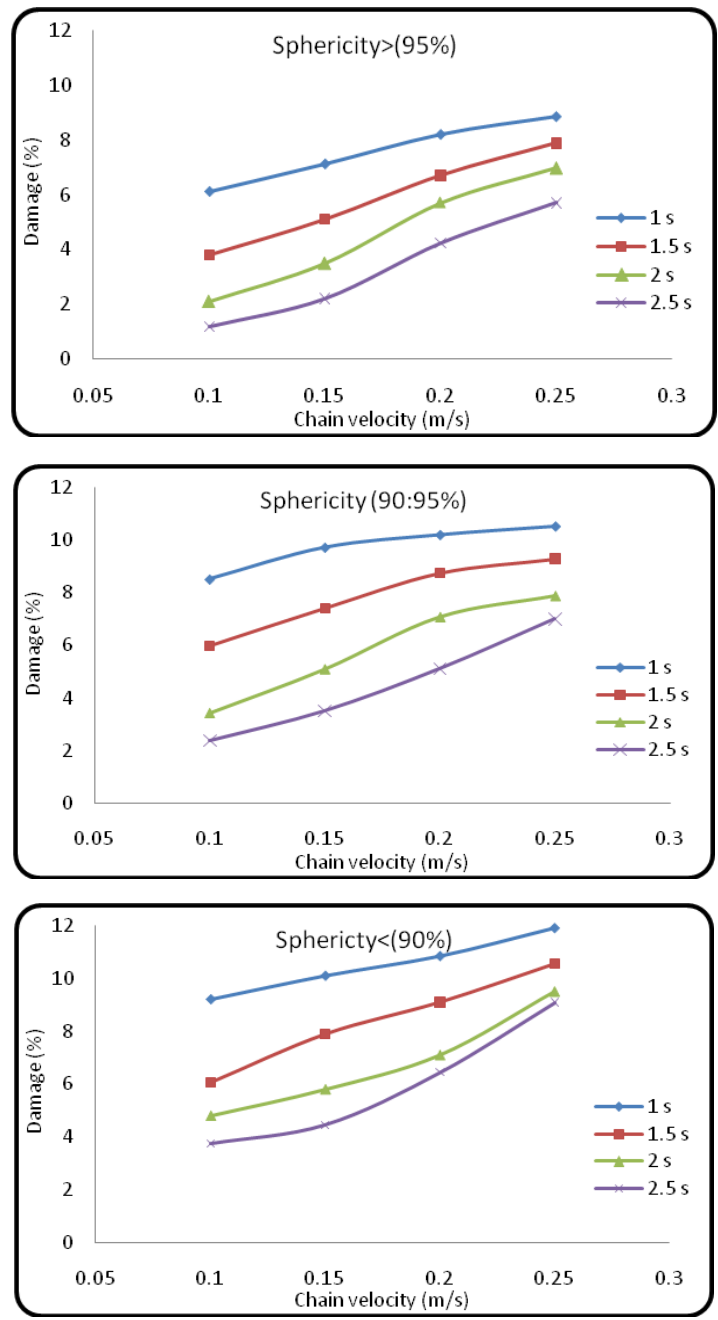

Fig. (9): Effect of chain velocity on damage percentage efficiency at different value of stopping time and sphericity percentage for orange.

\subsection{The energy}

The power required decreased when the stopping time increases from 1 to $2.5 \mathrm{sec}$ for all conveyor chain velocity. Also, increasing the conveyor chain velocity increased the energy required. The 
average value at $0.20 \mathrm{~m} / \mathrm{s}$ conveyor chain velocity, $1.5 \mathrm{sec}$ stopping time and $1 \mathrm{sec}$ measurement delay time was $160.2 \mathrm{Watt} / \mathrm{h}$ for orange .as shown in fig. (10).

\subsection{The productivity}

From figure (11) it shown that, increasing the chain velocity from 0.1 to $0.25 \mathrm{~m} / \mathrm{s}$ tended to increase the total productivity of the grading prototype for all the stopping time periods. Increasing stopping time from 1 to $2.5 \mathrm{sec}$ tended to decrease the total productivity of the grading prototype. The highest productivity of grading prototype for orange $(527 \mathrm{~kg} / \mathrm{h})$ was observed at the interaction of $0.25 \mathrm{~m} / \mathrm{s}$ conveyor chain velocity and $1 \mathrm{sec}$ stopping time. While, the lowest productivity of grading prototype (220 $\mathrm{kg} / \mathrm{h}$ ) was observed at the interaction of $0.1 \mathrm{~m} / \mathrm{s}$ conveyor chain velocity $2.5 \mathrm{sec}$ stopping time.

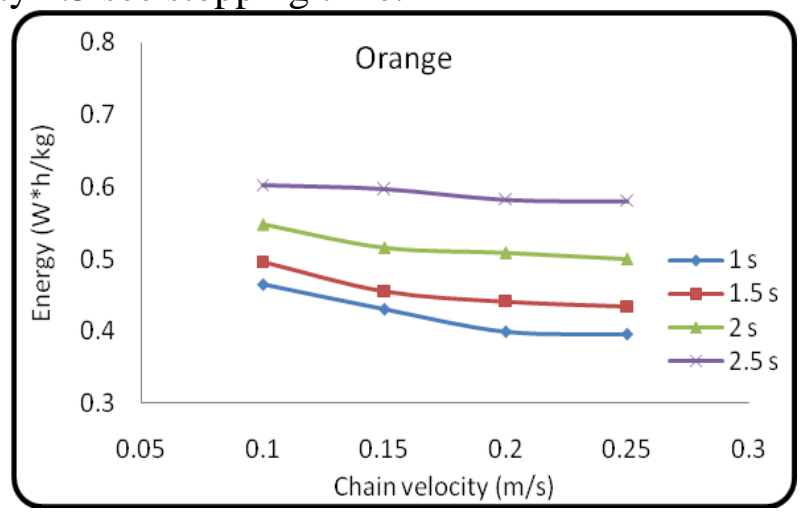

Fig.(10): Effect of conveyor chain velocity and stopping time on energy required for grading prototype .

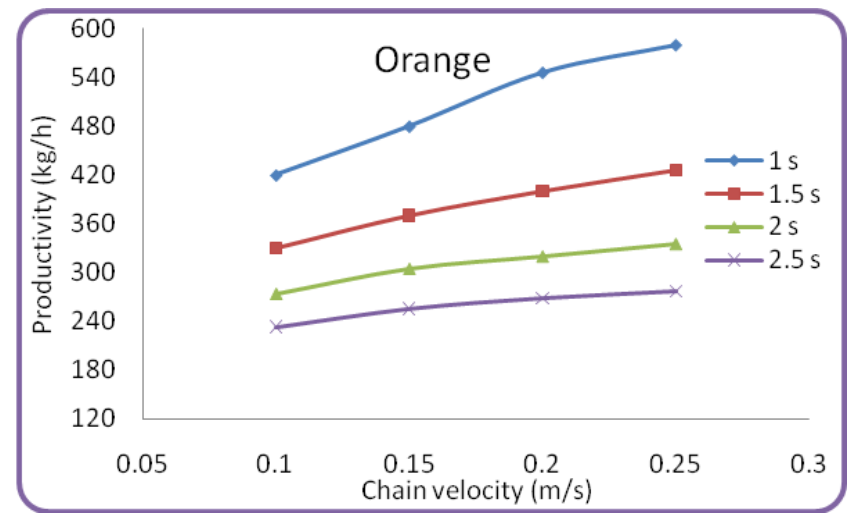

Fig.(11): Effect of conveyor chain velocity and stopping time on productivity of grading prototype. 


\subsection{Economic evaluation}

The cost evaluation of the prototype was performed at the best results of damage percentage, best efficiency and higher productivity at grading operations for orange. As the best velocity of the conveyor chain was $0.20 \mathrm{~m} / \mathrm{s}$ and a period of $1.5 \mathrm{sec}$ stopping time. The cost of materials and manufacturing of the final grading prototype was 10000 L.E. The cost of grading prototype per hour was (4.918 L.E/h).

\section{CONCLUSION}

Increasing the conveyor chain velocity from 0.10 to $0.25 \mathrm{~m} / \mathrm{s}$ led to increased the productivity but it led to decreased the prototype efficiency and increased the percentage of damage at all different factors. The grading efficiency increased with increasing the stopping and delay of measurement time. As well as increasing the stopping time lead to decreased the percentage of damage, but also decreased the prototype productivity. The best degrees of grading efficiency obtained with the best degrees of damage percentage were at $0.15 \mathrm{~m} / \mathrm{s}$ chain velocity and $1.5 \mathrm{sec}$ Stopping time. The highest obtained values of grading efficiency were $(92.2 \%)$ with $(7.1 \%)$ damage fruit. the energy required was 160.2 Watt $/ \mathrm{h}$. The cost of materials and manufacturing of the final grading prototype was 10000 L.E. The cost of grading prototype per hour was (4.918 L.E).

This prototype of grading succeeded for purpose as a step forward to the complete design for optimal grading machine.

\section{REFERANCES}

Awady, M. N. (1978), Engineering of tractors and agricultural machinery, Text book., col. Of Agric., Ain Shams Univ., $5^{\text {th }}$ Ed.: 164-167.

Brennan J. G. (2006). Food Processing Handbook. Chapter(1) Postharvest Handling and Preparation of Foods for Processing.

Klenin, N. I.; I. F. Popov and V. A. Sakun, (1985), Agricultural Machines (Theory of operation, computation of controlling parameters and the conditions of operation). Amerind publishing co. PVT. LTD. New York. 
Kondo, N. (2009), Automation on fruit and vegetable grading system and food traceability", Trends in Food Science \& Technology, doi: 10.1016/j.tifs.

Leemans, V. and M.F. Destain (2004), A real-time grading method of apples based on features extracted from defects Journal of Food Engineering $61: 83-89$

Mcgechan, M. B. (1980), An investigation into the damage sustained by different varieties of potatoes during ridding to removal soil. J. Agric. Eng. Res. V. n. 4, 345-353.

Moreda, G.P., J. Ortiz-Caavate, F.J. Garc-Ramos, M. Ruiz-Altisent. (2009),Non-destructive technologies for fruit and vegetable size determination - a review, Journal of Food Engineering (92): 119-136.

Mohsenin, N.N. (1970). Physical Properties of Plant and Animal Materials. New York: Gordon and Breach.

Ozer, K., B. A. Engel, J. E. simon (1995), Fusion classification techniques for fruit quality. ASAE. 38(6): 1927-1934.

Sudhakara R. R. and S. Renganathan (2002), New Approaches for Size Determination of Apple Fruits for Automatic Sorting and Grading. Iranian journal of electrical and computer engineering, vol.1, no. 2: 90-97.

Tabatabaeefar, A. A. Vefagh-Nematolahee, and A. Rajabipour. (2000), Modeling of orange mass based on dimentions. J. Agr. Sci. tech. vol. 2:299-305.

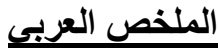

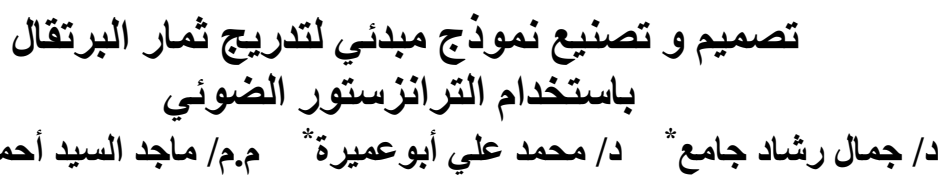

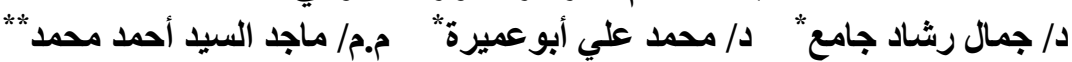

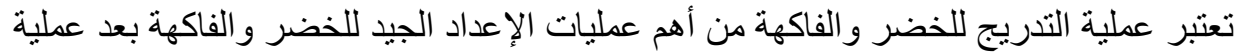

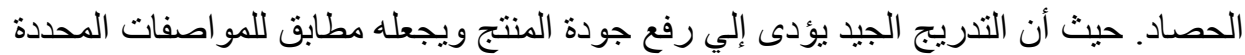

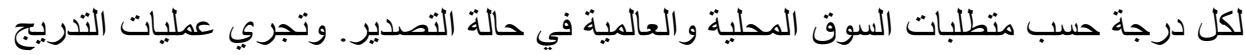

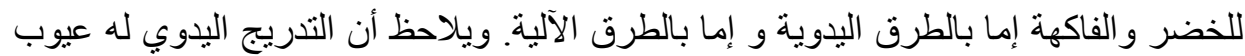

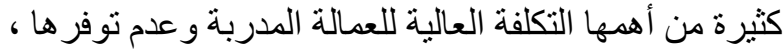

* أستاذ مساعد بقسم الهندسة الزراعية ـ كلية الزراعة ـ جامعة المنوفية

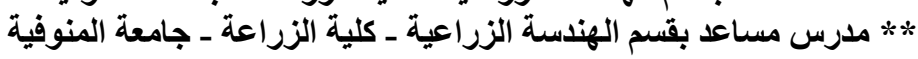


وكذلك انخفاض معدل إنتاجها وكفاءتها بالإضافة إلي تعرض المنتجات للتلوث. ب بينما تتميز

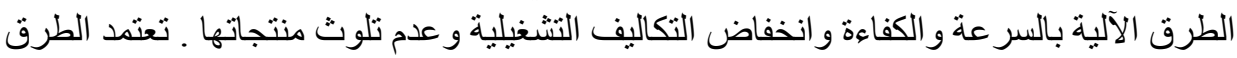

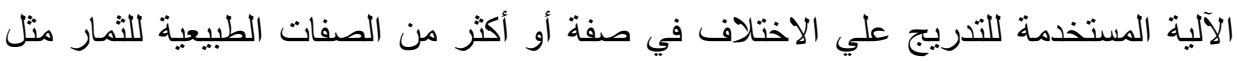

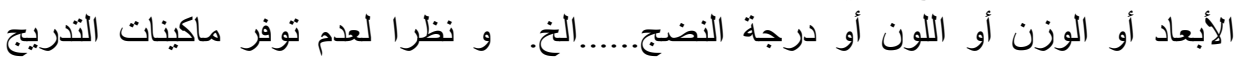

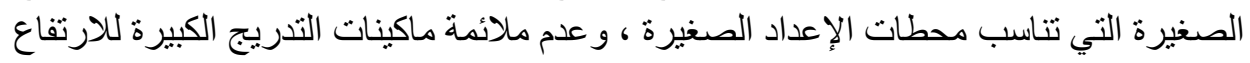

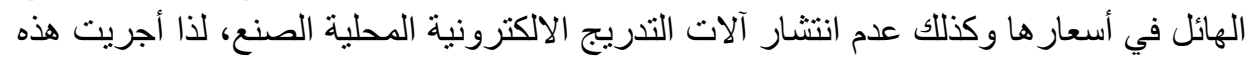

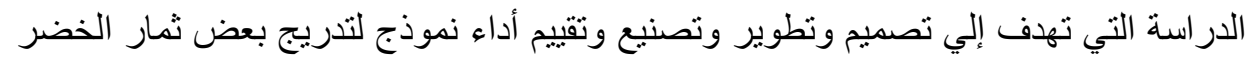

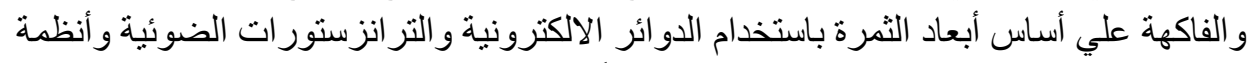

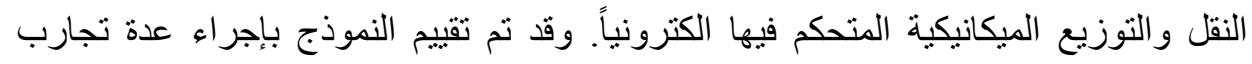

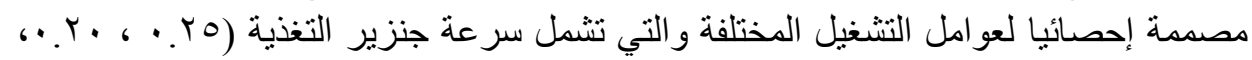

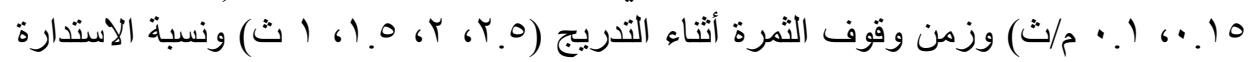

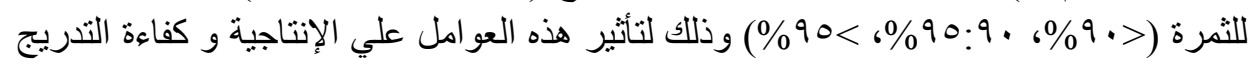

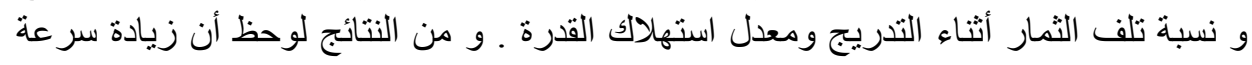

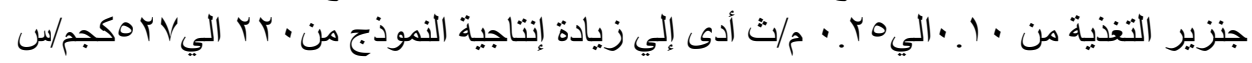

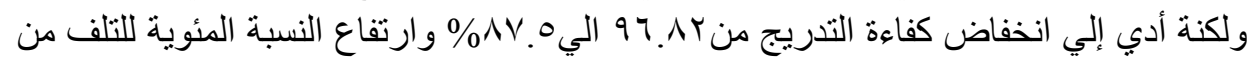

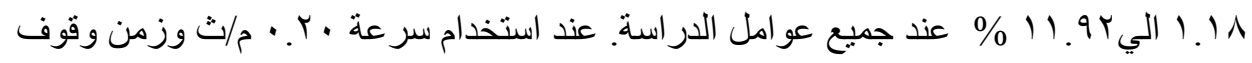

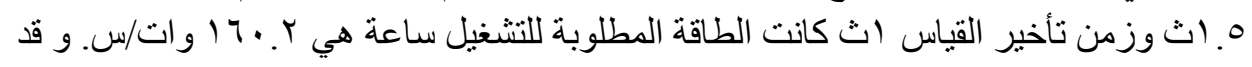

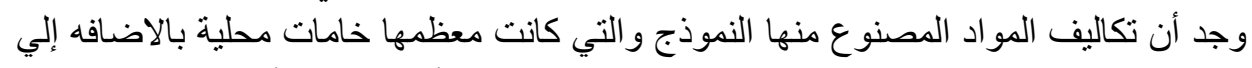

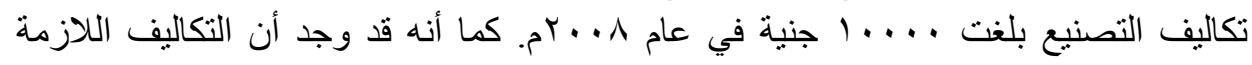

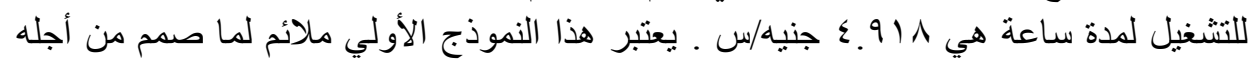

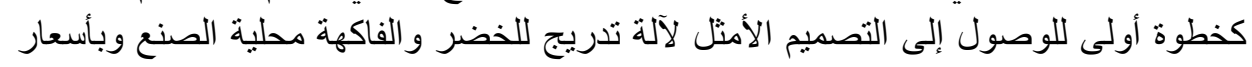

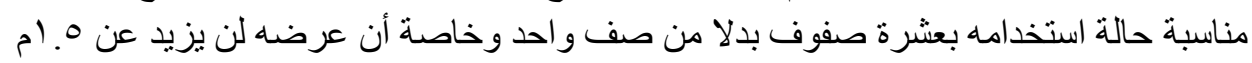
كدر اسات مستقبلية. 